\section{Microwave Cryofixation}

Lee van Hook

Piltdown Research Institute, Munchausen University

There is much discussion on the best way to fix biological specimens, often advocating cryofixation or microwave fixation. These discussions sometimes become acrimonious, and we at the P.R.I. fear the eventual division of microscopists into rival lab gangs, the "Waves" and the "Cryos".

Wishing to forestall this, and because Leonard Bernstein is no longer with us to write West Lab Story, we have been working on a method of combining the two fixation methods. Less romantic than rival gang members falling in love perhaps, but more practical.

The basic premise is this: microwave radiation is obviously periodic, as is the motion of molecules. Heating occurs when microwaves of a specific frequency interact in some manner with the motions of particular molecules, the frequency determining with which molecules (or bonds) the microwaves interact. The physics of this are poorly understood, but since both the microwaves and the molecular motions are periodic phenomena, it may be assumed that absorption of microwave energy is strongest when the microwave frequency resonates with the target molecule's motion. The microwave therefore stimulates the molecule's motion, and so heating occurs.

Well then, if this is so, what happens with the microwave is $180^{\circ}$ out of phase with the target molecule's motion? The microwave ought to cancel the molecule's motions, the way out-of-phase sound waves cancel out each other (something well known to those who have bought noise-cancelling headphones and are no longer subjected to crying-baby syndrome on long plane flights). This cancellation quiets the molecule's motions, resulting in cooling instead of heating. Fantastic as this may sound, it is no stranger than bombarding fast moving atoms with lasers to slow (that is, cool) the atoms to near absolute zero.

The obvious objection is that the molecular motions are random, and need to be synchronous to be cooled by the out-of-phase microwaves. The same argument applies to heating, since the heating results from the interaction of the microwaves and molecules and isn't just an increase in the kinetic energy of moving molecules or atoms (as when water is boiled on a stone). In the usual case, random interaction leads to increased friction, and therefore heating. If random interaction leads to decreased friction or motion in the majority of molecules, we get cooling.

Regular microwave processors use a water load to help balance the power in the oven, and keep the heating even. There is a need for analog of this in cryofixation, and we have found frozen daiquiris excellent for this purpose.

The great advantage to microwave cryofixation is much the same as for microwave heating: the temperature of the specimen is affected throughout its volume. This means that larger specimens can be cryofixed than before. Also, with properly tuned microwaves, very rapid cooling rates can be achieved, so amorphous freezing occurs deep in the specimen, and not just In a 10 or $100 \mu \mathrm{m}$ surface layer.

How exactly the microwaves interact with the specimen to achieve this freezing is of course proprietary information (OK, we don't understand it either), but readers can expect the P.R.I. line of CryoWave ${ }^{\text {eTMo }}$ ovens to be on the market as soon as our technology-transfer division, Oxymoron Inc., is in business.
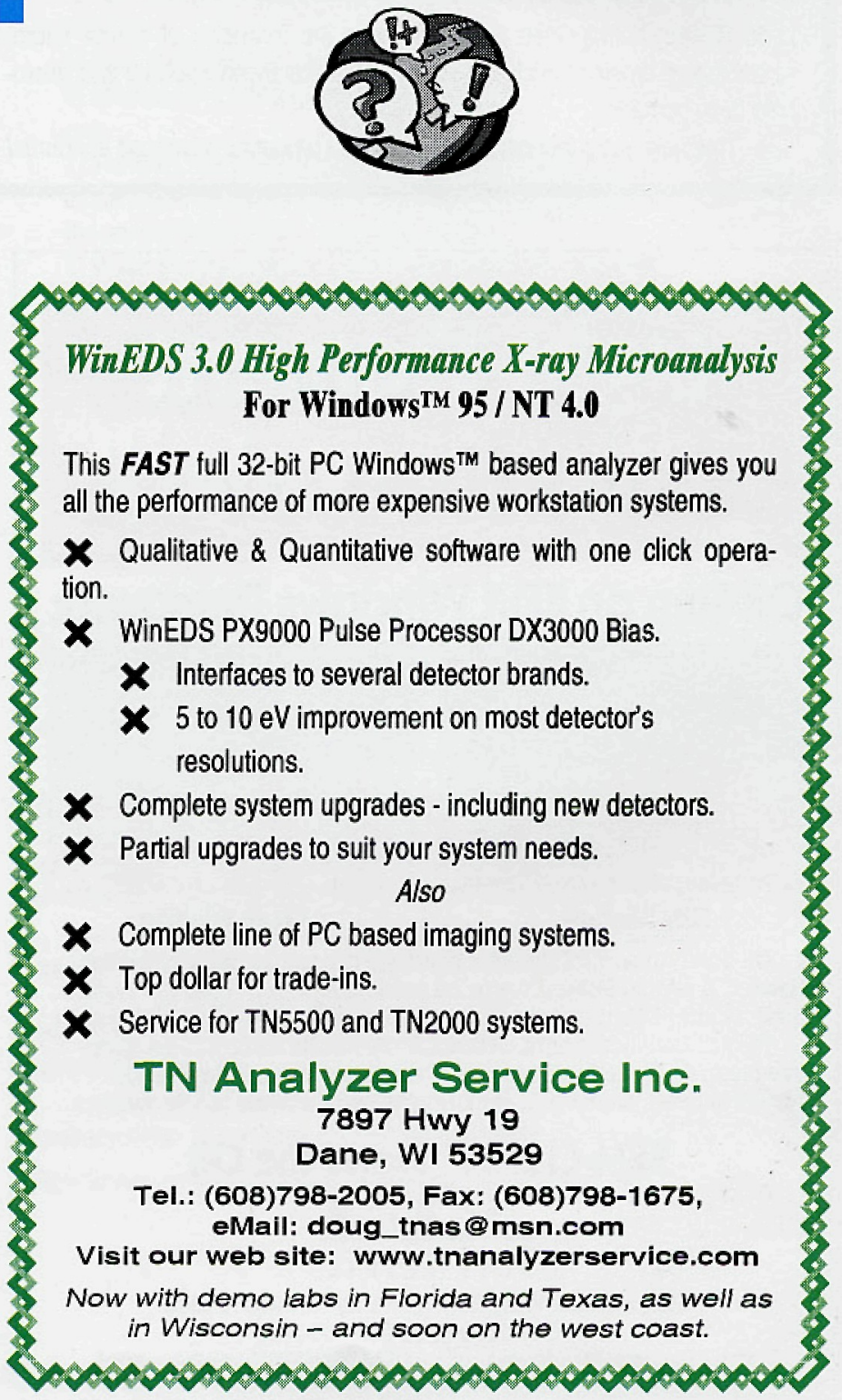

\section{True Photographic Prints from Digital Files. \\ FUJI PICTROGRAPHY $3000 / 4000$ \\ FUJIFILM}

HIGH SPEED PRINTING.

\section{HIGH RESOLUTION.}

The PG 3000 color printer produces clean, true photographic prints from digital files.

No hazardous chemicals to mix or discard.

The PG 4000 is the natural output choice when you need to capture, analyze and store color images for scientific and medical research tasks such as remote sensing, image analysis and simulations. Maximum print sizes:

$P G 300081 / 2 \times 11, P G 400012 \times 18$

The one-stop source since 1927 for nie imaging equipment \& suppllos
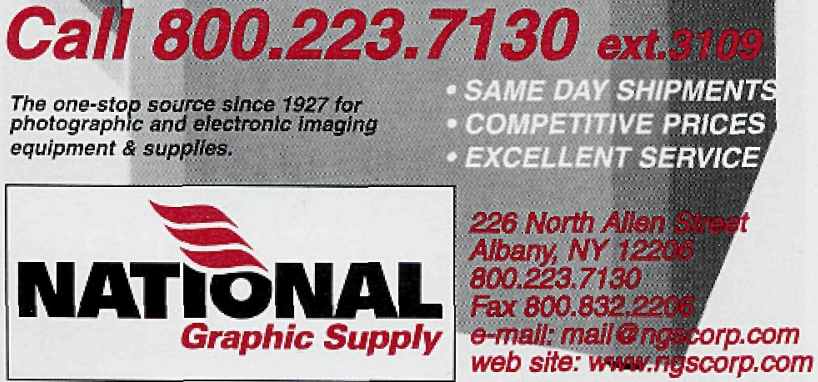

IsI-Imaging a Information

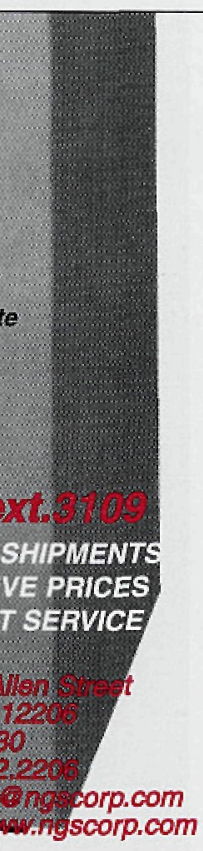




\section{coming avenits}

McCrone Research Institute (Selected) Microscopy Courses, Chicago, IL Nov 9/13 '98: Particle Isolation, Manipulation and Mounting for Additional Analysis

Nov 30/Dec 4 '98: Scanning Electron Microscopy

March 1/5 '99: Conoscopic Methods

April 12/16 '99: An Introduction to TEM - Techniques and Applications April 12/16 '99: Advanced FTIR Microscopy

June 21/25 '99: Electronic Image Acquisition, Processing \& Analysis

Nancy Daerr: (312)842-7100, Fax: (312)842-1078, ndaer@mcri.org

$\checkmark$ Nov 2/3 '98: Image Analysis Workshop (Univ. of Maryland) College Park, MD. Dr. John Russ: (301)495-5964, email: http.//www.mediacy.com

$\checkmark$ Nov 2/6 '98: 45th International Symposium Covering Thin Films, Microelectronics, Nanostructures, Processing, Surfaces, and Vacuum (AVS), Baltimore, MD. AVS: (212)248-0200, avsnyc@vacuum.org

$\checkmark$ Nov 15/20 98: 37th Eastern Analytical Symposium and Exposition. Somerset, NJ. (302)738-6218, Fax. (302)738-5275, Email: easinfo@aol.com

$\checkmark$ Nov 11 '98: 28th Scottish Microscopy Group Symposium. University of Dundee: http://www.abdn.ac uk/ nhi691/smg98.htm

$\checkmark$ Nov 15/20 98: 1998 Eastern Analytical Symposium. Somerset, NJ, (302)738-6218, easinfo@aol.com

$\checkmark$ Nov 16/20 '98: Scanning Electron Microscopy \& X-ray Microanalysis (SUNY), New Paltz, NY. Dr. A.V. Patsis, (914)255-0757, Fax: (914)255-0978, email: inquiries@ims-np.org

$\checkmark \quad$ March 7/12 '99: PITTCON '99. Orlarido, FL (412)825-3220, Fax: (412) 825-3224, email: expo@pittcon.org

$\checkmark$ March 22/25 '99: 11th International Conference on Microscopy of Semiconducting Materials. (RMS \& MRS) University of Oxford. hitip./Www. lop. org/Confs

$\checkmark$ April 11/14 '99: SCANNING '99: (FAMS, Inc) Chicago, IL, Mary K. Sullivan: (201)818-1010, Fax: (201)818-0086, fams@holonet.net

$\checkmark$ April 11/15 99: FOCUS ON MICROSCOPY 1999 - 12th International Conference on 3D Image Processing in Microscopy \& 11th Internation Conference on Confocal Microscopy (European Molecular Biology Laboratory). Heidelberg, Germany http://www.embl-heidelberg.de/Conferences/ FocusOnMicroscopy

$\checkmark \quad$ LEHIGH MICROSCOPY SCHOOL, Bethlehem, PA

June 14/18 '99: SEM and X-ray Microanalysis

June 13 ' 99 : Introduction to SEM and EDS

June 21/25' 99 : Advanced Scanning Electron Microscopy

June 21/25 99: Quantitative X-ray Microanalysis

June 21/24 99: Analytical Electron Microscopy

June 22/25 99: Atomic Force Microscopy

June 21/24 99: Microdiffaction

Info: Ms Sharon Coe: (610)758-5133, email: slc6@lehigh.edu

$\checkmark$ June 16/27 '99: 3D Microscopy of Living Cells \& June 29/July1'99:3D Image Processing Workshop (Univ of British Columbia) Vancouver, BC, Canada. Prof. James Pawley: (608)263-3147, jbpawley@facstaff.wisc edu

$\checkmark$ June 21/25 '99: 15th Annual Short Course on Molecular Microspectroscopy (Miami Universtiy) Oxford, $\mathrm{OH}$ (513)529-2874, fax: (513)5297284, email: http://Www muohio edu/-sommeraj

$\checkmark$ Aug 1/5 '99: MICROSCOPY \& MICROANALYSIS ' 99 (MSA) Portland, OR

$\checkmark$ April 11/13 '00: MICRO 2000 (Royal Microscopical Society) London

$\checkmark$ June 26/30 '00: 7th Asia-Pacific Conference on Electron Microscopy Singapore. eMail: micngml@nus.edu.sg or medlab2@nus.edu.sg http://www.med.nus.edu.sg/micsoc/7apem

$\checkmark$ July $9 / 14$ '00. 12th European Congress on Electron Microscopy. Bruno, Czech Republic. http://www eurem2000 isibrno.cz/

\section{Introducing the No Cost EDS Upgrade ${ }^{*}$}

\section{*Upgrade your EDS system for less than you currently spend for maintenance fees}

\section{Good}

The lowest cost way to attach a PC to your existing system. You won't believe the price.

- MCA4002

- Qualitative software

\section{Better}

Complete upgrade includes everything but the detector. Provides the best value in the market.

\section{- System 4004}

Spectrometer - Pulse

Processor, Bias, MCA

- Pentium PC and Color Printer

- Fully quantitative software

\section{Best}

Add a complete detector rebuild to UTW window and premium performance. Great performance at a fraction of the price of a new system.

- Detector rebuild to UTW and premium resolution

- System 4004 Spectrometer - Pulse Processor, Bias, MCA

- Pentium PC and Color Printer

- Fully quantitative software
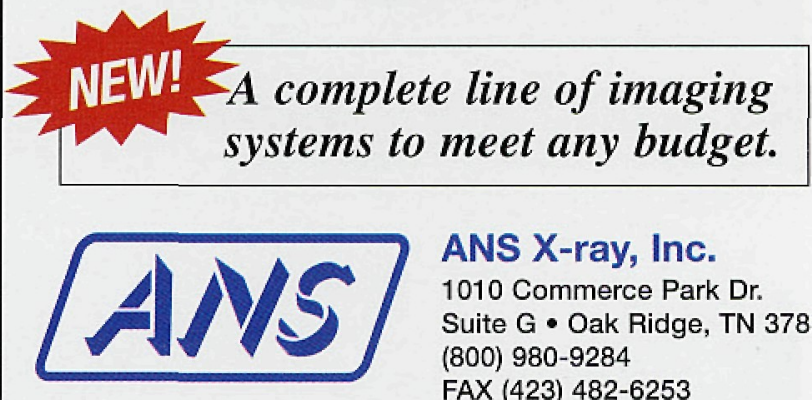

ANS X-ray, Inc.

1010 Commerce Park Dr.

Suite G • Oak Ridge, TN 37830 (800) $980-9284$

FAX (423) 482-6253

Email: sales@ansxray.com

Visit our web site: www.ansxray.com for complete details and free demo software 